\title{
Increased arachidonic acid incorporation into platelet phospholipids in Type 2 (non-insulin-dependent) diabetes
}

\author{
R. Takahashi ${ }^{1}$, I. Morita ${ }^{2}$, Y.Saito ${ }^{1}$, H. Ito ${ }^{1}$ and S. Murota ${ }^{2}$ \\ ${ }^{1}$ Endocrinology and Metabolism Section, Tokyo Metropolitan Geriatric Hospital and \\ ${ }^{2}$ Department of Pharmacology, Tokyo Metropolitan Institute of Gerontology, Tokyo, Japan
}

\begin{abstract}
Summary. Arachidonic acid uptake activity was measured in platelets obtained from 27 Type 2 diabetic patients and 18 agematched control subjects. In both groups after $1 \mathrm{~h}$ incubation almost all the incorporated ${ }^{14} \mathrm{C}$-arachidonic acid was located in the phospholipids of the platelets. Arachidonic acid was predominantly incorporated into phosphatidylcholine. The radioactivity incorporated into platelets increased linearly with incubation time, up to $90 \mathrm{~min}$. The linear increase was observed at arachidonic acid concentrations of $0.1-1.0 \mu \mathrm{g} / \mathrm{ml}$ in both groups. The rate of incorporation of radioactivity in diabetic platelets was about 1.4 times higher than that in control platelets at all arachidonic acid concentrations studied. The arachidonic acid uptake activity of diabetic platelets $\left(577 \pm 26 \mathrm{ng} / 60 \mathrm{~min}\right.$ per $10^{9}$ platelets) was significantly higher than that in control platelets $\left(410 \pm 26 \mathrm{ng} / 60 \mathrm{~min}\right.$ per $10^{9}$ platelets).
\end{abstract}

No significant correlations were found between the arachidonic acid uptake activity and fasting plasma glucose, total cholesterol or triglyceride levels. The arachidonic acid uptake activity of platelets was significantly higher in diabetic patients with proliferative retinopathy than in those with little or no background retinopathy. In addition, there were no significant differences between control and diabetic subjects in the uptake activity of platelets for linoleic acid and oleic acid. These data may explain the elevated arachidonic acid content in diabetic platelet phospholipids and enhancement of thromboxane synthesis in diabetes.

Key words: Arachidonic acid uptake, platelet phospholipids, Type 2 diabetes, retinopathy, platelet-rich plasma, non-esterified fatty acid.
Thromboxane $\mathrm{A}_{2}\left(\mathrm{TXA}_{2}\right)$, biosynthesized from arachidonic acid in platelet phospholipids, plays an important rôle in the process of platelet aggregation [1,2]. It is postulated that the balance between platelet $\mathrm{TXA}_{2}$ and vascular prostacyclin production might be a crucial step in the development of atherosclerosis and arterial thrombosis in diabetes mellitus. Recently, Kalofoutis and Lekakis [3] and we [4] have demonstrated that the arachidonic acid content of platelet phospholipids was increased in diabetes. It is generally accepted that the $\mathrm{TXA}_{2}$ synthesis rate is regulated at the step of liberation of arachidonic acid from membrane phospholipids [5]. Therefore, increased esterified arachidonic acid content in phospholipids might modulate $\mathrm{TXA}_{2}$ production in diabetes.

In this study, we examined the ${ }^{14} \mathrm{C}$-arachidonic acid uptake activity of platelets obtained from Type 2 (noninsulin-dependent) diabetic patients and age-matched control subjects, to clarify the mechanisms of increased arachidonic acid levels in platelet phospholipids in diabetes.

\section{Subjects and methods}

\section{Subjects}

The Type 2 diabetic subjects included in the study were 10 men and 17 women ranging in age between 48 and 86 years (mean $67 \pm 2$ years). Eleven patients were treated with insulin and 16 were treated with sulphonvlureas. The control subjects (five men and 13 women, age range $46-79$ years, mean $69 \pm 2$ years) had no history of diabetes or any other disease that would alter platelet aggregation. No subject had taken aspirin or any other drugs which might alter prostaglandin metabolism during the previous 2 weeks. Fasting plasma glucose levels were $4.94 \pm 0.11 \mathrm{mmol} / \mathrm{l}$ in the control subjects and $9.89 \pm 0.94$ $\mathrm{mmol} / \mathrm{l}$ in the diabetic patients $(p<0.001)$. Nineteen patients had diabetic retinopathy (11 background retinopathy and 8 proliferative retinopathy), and four with proliferative retinopathy also had persistent proteinuria. In the diabetic group, six patients had a history of cerebral infarction. No patient had a history of myocardial infarction.

\section{Assay for non-esterified acid uptake activity of platelets}

Venous blood was collected from an antecubital vein by a citrated plastic syringe. The final ratio between $3.8 \%$ citrate and blood was adjusted to 1:9. Platelet-rich plasma was prepared by centrifugation of blood at $110 \mathrm{~g}$ for $10 \mathrm{~min}$ at room temperature. The platelet-rich plas- 
ma was recentrifuged at $990 \mathrm{~g}$ for $20 \mathrm{~s}$ to remove erythrocytes. The final platelet concentration in the platelet-rich plasma was $1.6-4.9 \times 10^{8}$ cells $/ \mathrm{ml} .{ }^{14} \mathrm{C}$-labelled fatty acids $(1 \mu \mathrm{g})$ (specific activity $=58.4 \mathrm{Ci} /$ $\mathrm{mol}$ for ${ }^{14} \mathrm{C}$-arachidonic acid, $56.0 \mathrm{Ci} / \mathrm{mol}$ for ${ }^{14} \mathrm{C}$-linoleic acid and $59.9 \mathrm{Ci} / \mathrm{mol}$ for ${ }^{14} \mathrm{C}$-oleic acid, respectively, Amersham International, Bucks, UK) suspended in $50 \mu 1$ of $100 \mathrm{mmol} / 1$ Tris buffer (pH 9.0) with a small amount of propyleneglycol were added into $1 \mathrm{ml}$ of platelet-rich plasma. Incubation was carried out at $30^{\circ} \mathrm{C}$ for 60 min unless otherwise indicated and was terminated by centrifugation of the incubation mixture at $990 \mathrm{~g}$ for $10 \mathrm{~min}$ at $4{ }^{\circ} \mathrm{C}$. The radioactivities of both the supernatant and the platelet pellet were counted by a liquid scintillation counter (Beckmann, California, USA).

\section{Fractionation of platelet lipids}

Platelet lipids were extracted from labelled platelet samples and separated by centrifugation of the mixture according to the method of Bligh and Dyer [6]. Separation into neutral lipid, non-esterified fatty acid (NEFA) and phospholipids was carried out by thin-layer chromatography with the following solvent system; n-hexane: diethyl ether: acetic acid (90:10:1, by volume). After development, the phospholipid zone was scraped off and then extracted with chloroform: methanol ( $1: 2$, by volume), and subfractionation of phospholipids was conducted by thin-layer chromatography with the solvent system of chloroform: methanol: acetic acid: water ( $75: 45: 12: 3$, by volume). Because phosphatidylinositol and phosphatidylserine showed the same $R_{F}$ value in this solvent system, the phosphatidylinositol and phosphatidylserine zone was scraped and rechromatographed using the solvent system chloroform: methanol: acetic acid: formic acid: water $(45: 10: 1: 5: 1$, by volume) [7]. The radioactivities were detected by a Dünnschicht-scanner II (Laboratories Berthold, Wildbad, FRG) and the zones corresponding to the appropriate phospholipid standards were scraped off for the measurement of radioactivity by a liquid scintillation counter (Beckmann).

\section{Biochemical assays}

Fasting plasma glucose levels were estimated by a glucose-oxidase method using a Glucoroder-S automated glucose analyzer (Analytical Instruments, Tokyo, Japan). Plasma total cholesterol (Cholescolor-auto, Tokoboseki, Osaka, Japan [8] and triglyceride (Lipidos-auto N, Toyoboseki, Osaka, Japan) [9] were measured by an enzymatic colorimetric method. Plasma NEFA levels were assayed using an enzymatic spectrophotometric technique (Iatro-MA 701 NEFA, Iatron Laboratories, Tokyo, Japan) [10].

\section{Statistical analysis}

Results are presented as mean \pm SEM. Statistical analysis was performed by Student's two-tailed t-test.

\section{Results}

When platelet-rich plasma was incubated with ${ }^{14} \mathrm{C}$-arachidonic acid, approximately $15 \%$ of the radioactive arachidonic acid was taken up into platelets after $1 \mathrm{~h}$. Radioactivity $(99.4 \%)$ was incorporated into the phospholipid fraction. The effect of time on arachidonic acid incorporation into platelets is shown in Figure 1. The radioactivity incorporated into platelets increased linearly with time up to $90 \mathrm{~min}$ in both groups. The levels of uptake activity in diabetic patients were higher than in control subjects throughout the experiment. The radioactivity incorporated into platelets increased proportionally according to the increase in substrate con-

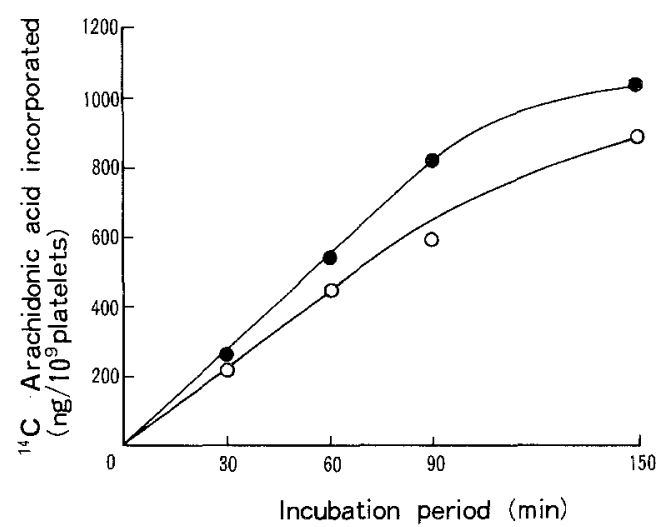

Fig. 1. Effect of incubation period on arachidonic acid uptake activity in platelets. Each point represents the mean of duplicate assays. Platelet-rich plasma was obtained from: $\mathrm{O}-\mathrm{O}$ control subjects; - diabetic patients. Each point represents the mean of three different subjects

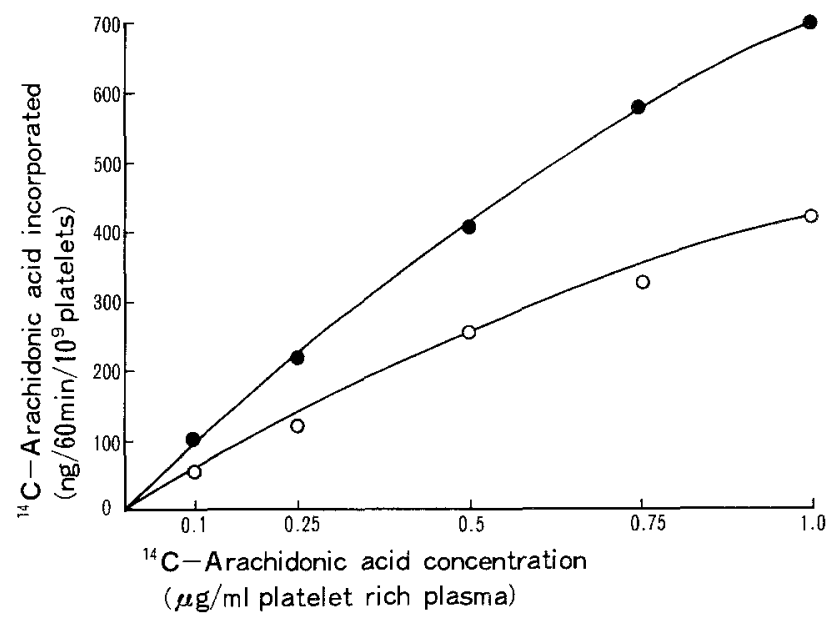

Fig. 2. Effect of concentrations of ${ }^{14} \mathrm{C}$-arachidonic acid on arachidonic acid uptake activity in platelets from: $\mathrm{O}-\mathrm{O}$ control subjects; diabetic patients. Each point represents the mean of two different subjects. Duplicate assays were performed in each subject at each time-point indicated

centration $(0.1-1.0 \mu \mathrm{g} / \mathrm{ml}$ platelet-rich plasma) in both control and diabetic platelets (Fig. 2).

There was a linear relationship between arachidonic acid uptake activity and platelet numbers ranging from 1.6 to $4.9 \times 10^{8}$ cells $/ \mathrm{ml}$ platelet-rich plasma. We could not find any significant difference in the platelet concentration in platelet-rich plasma between control and diabetic subjects $\left(2.49 \pm 0.17 \times 10^{8}\right.$ and $2.35 \pm$ $0.14 \times 10^{8}$ cells $/ \mathrm{ml}$, respectively).

As summarized in Figure 3, the arachidonic acid uptake activity of diabetic platelets was significantly higher than that in control platelets $(577 \pm 26$ versus $410 \pm$ $26 \mathrm{ng} / 60 \mathrm{~min}$ per $10^{9}$ platelets, $p<0.001$ ). Among the diabetic group, platelets obtained from patients with proliferative retinopathy had significantly greater activity than those from patients with little or no background retinopathy $(696 \pm 45$ versus $526 \pm 25 \mathrm{ng} / 60 \mathrm{~min}$ per $10^{9}$ platelets, $\left.p<0.01\right)$. 


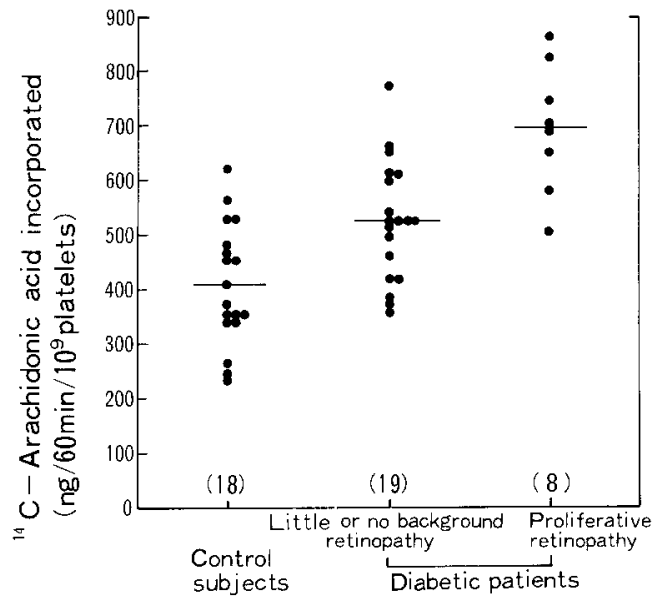

Fig. 3. The incorporation of ${ }^{14} \mathrm{C}$-arachidonic acid into platelet phospholipids in control and diabetic subjects. Number of subjects in each group is shown in parentheses, and line represents mean in each group

Table 1. Distribution of ${ }^{14} \mathrm{C}$-arachidonic acid incorporated into platelet phospholipids in control and diabetic subjects

\begin{tabular}{lrlr}
\hline $\begin{array}{l}\text { Phospholipids } \\
\text { (ng/60 min per }\end{array}$ & $\begin{array}{l}\text { Control } \\
\text { subjects } \\
(n=3)\end{array}$ & $\begin{array}{l}\text { Diabetic } \\
\text { patients } \\
(n=4)\end{array}$ & Difference $^{\mathrm{a}}$ \\
\hline platelets) & $243 \pm 19$ & $350 \pm 21$ & 107 \\
\hline Phosphatidylcholine & $58 \pm 16$ & $76 \pm 9$ & 18 \\
Phosphatidylinositol & $27 \pm 5$ & $73 \pm 8$ & 46 \\
Phosphatidylserine & $61 \pm 15$ & $103 \pm 16$ & 42 \\
Phosphatidylethanol- & & & \\
$\quad$ amine & &
\end{tabular}

a Difference $=$ (mean value of diabetic patients) - (mean value of control subjects). Results expressed as mean \pm SEM

Table 2. The incorporation of ${ }^{14} \mathrm{C}$-labelled fatty acid into platelet phospholipids in control and diabetic subjects

\begin{tabular}{lcl}
\hline (ng/60 min per 109 platelets) & $\begin{array}{l}\text { Control subjects } \\
(n=8)\end{array}$ & $\begin{array}{l}\text { Diabetic patients } \\
(n=9)\end{array}$ \\
\hline Arachidonic acid uptake & $428 \pm 50$ & $613 \pm 40^{\mathrm{a}}$ \\
Linoleic acid uptake & $75 \pm 16$ & $82 \pm 13$ \\
Oleic acid uptake & $77 \pm 16$ & $85 \pm 13$
\end{tabular}

${ }^{a} p<0.01$ versus control subjects. Results expressed as mean $\pm \mathrm{SEM}$

Table 3. Relationship between ${ }^{14} \mathrm{C}$-labelled fatty acid uptake in platelets and plasma biochemical variables in diabetic subjects

\begin{tabular}{clllll}
\hline & & $\begin{array}{l}\text { Fasting } \\
\text { plasma } \\
\text { glucose }\end{array}$ & NEFA & $\begin{array}{l}\text { Total } \\
\text { choles- } \\
\text { terol }\end{array}$ & $\begin{array}{l}\text { Trigly- } \\
\text { ceride }\end{array}$ \\
\hline $\begin{array}{c}\text { Arachidonic } \\
\text { acid uptake }\end{array}$ & $(n=27)$ & $\mathrm{NS}$ & $\mathrm{NS}$ & $\mathrm{NS}$ & $\mathrm{NS}$ \\
$\begin{array}{c}\text { Linoleic acid } \\
\text { uptake }\end{array}$ & $(n=9)$ & $\mathrm{NS}$ & $\begin{array}{l}r=-0.807 \\
p<0.01\end{array}$ & $\mathrm{NS}$ & $\mathrm{NS}$ \\
$\begin{array}{c}\text { Oleic acid } \\
\text { uptake }\end{array}$ & $(n=9)$ & $\mathrm{NS}$ & $\begin{array}{l}r=-0.826 \\
p<0.01\end{array}$ & $\mathrm{NS}$ & $\mathrm{NS}$ \\
\hline
\end{tabular}

$\mathrm{NS}=$ not significant
A more detailed examination of the distribution of incorporated ${ }^{14} \mathrm{C}$-arachidonic acid in platelet phospholipids was performed. Arachidonic acid was predominantly incorporated into phosphatidylcholine in both control and diabetic subjects (Table 1). Although statistical analysis could not be evaluated due to the small number of experiments, the incorporation of ${ }^{14} \mathrm{C}$-arachidonic acid into diabetic platelets tended to be higher than that into control platelets in all the phospholipid classes, especially in the phosphatidylcholine fraction.

To determine whether arachidonic acid uptake by diabetic platelets increased specifically, uptake activities for linoleic and oleic acid were examined simultaneously with those for arachidonic acid. The same trend of linearly increased linoleic and oleic acid incorporation into platelets was observed both in control and diabetic subjects up to $90 \mathrm{~min}$ incubation time. There were no significant differences in linoleic and oleic acid uptake between control and diabetic subjects (Table 2). The correlation between arachidonic acid uptake activity and plasma biochemical variable is shown in Table 3 . The arachidonic acid uptake had no significant correlation with any of these variables in diabetes. On the other hand, the linoleic and oleic acid uptake activities were found to have significant negative correlations with plasma NEFA levels in diabetes (both $p<0.01$ ).

\section{Discussion}

The accelerated platelet aggregation reported in diabetic patients suggests existence of abnormal arachidonic acid metabolism in diabetic platelets. TXA 2 , having an important rôle in platelet aggregation, is biosynthesized from arachidonic acid in platelet phospholipids. The arachidonic acid content in the phosphatidylcholine and phosphatidylinositol fraction is known to be an important modulating factor for $\mathrm{TXA}_{2}$ synthesis [3,11]. Therefore, increased arachidonic acid content in diabetic platelet phospholipids $[3,4]$ was considered as one possible cause of increased TXA $_{2}$ synthesis in diabetic platelets [12-14]. However, Jones et al. [15] recently reported a significant decrease in arachidonic acid levels in diabetic platelet phospholipids, a result quite different from ours. It has been demonstrated that the synthesis of prostaglandin precursors, polyunsaturated fatty acids, is influenced by insulin [16] and ageing [17]. Thus the discrepancy in results might be explained by a difference in type of diabetes: all the patients in our study had Type 2 diabetes, whereas the patients of Jones et al. probably had Type 1 diabetes as indicated by insulindependence and early onset of diabetes. Moreover, the difference in age of subjects (mean 45 years in their study and 67 years in ours) might be another possible reason. We demonstrated here that the accelerated arachidonic acid uptake activity of Type 2 diabetic platelets accounted for the increased arachidonic acid content in platelet phospholipids. 
Although the uptake of arachidonic acid is affected by the number of platelets, control and diabetic subjects were similar in this respect. Phospholipid phosphorus levels in platelets might possibly alter arachidonic acid uptake activity, but were similar in control and diabetic subjects in our preliminary data (not shown). The fatty acid uptake activity of platelets might be influenced by NEFA levels in platelets and plasma. Bills et al. [18], however, demonstrated that free arachidonic acid levels in platelets are negligible. Moreover, the plasma free arachidonic acid levels in diabetic patients, determined by chemical ionization gas chromatography/mass spectrometry analysis, did not differ from those in control subjects (approximately $1.0 \mathrm{mg} / 1$ in both groups). Thus, the accelerated ${ }^{14} \mathrm{C}$-arachidonic acid uptake activity of diabetic platelets may be involved in the quantitatively increased arachidonic acid content of platelets in diabetic patients.

The lack of significant correlation of arachidonic acid uptake activity of diabetic platelets with plasma NEFA levels, and the significant negative correlation of linoleic acid and oleic acid uptake with plasma NEFA levels (Table 3), are supported by our previous report [4]. We have now demonstrated a good correlation between the levels of fatty acids, excluding arachidonic acid, in platelet phospholipids and those in total plasma lipids. These results suggest that the fatty acid uptake activity of platelets is specifically accelerated for arachidonic acid in diabetic patients. The activity of an arachidonicacid-specific arachidonoyl CoA synthetase in platelets discovered recently by Wilson et al. [19], might be activated in the diabetic state.

The arachidonic acid uptake activity of platelets was significantly higher in the diabetic patients with proliferative retinopathy than in those with little or no background retinopathy (Fig.3). Production of TXA $\mathrm{TH}_{2}$ by platelets after ADP, arachidonic acid or thrombin stimulation was higher in the diabetic patients with microangiopathy than in those without complications [12-14, 20]. On the other hand, prostacyclin synthesis was decreased in the diabetic patients with microangiopathy [21]. It is important to elucidate the mechanisms of abnormal arachidonic acid metabolism in diabetes in order to understand the pathogenesis of vascular complications in this disease.

Acknowledgements. This investigation was kindly supported in part by a grant from the Tokyo Metropolitan Institute of Gerontology. We are indebted to Dr. M. Murakami (Director, Tokyo Metropolitan Geriatric Hospital, Tokyo, Japan) for his valued criticism. The personal support and interest of Dr. M. Shiraki is gratefully acknowledged. We are also grateful to Miss Y.Kanda for typing the manuscript.

\section{References}

1. Hamberg M, Svensson J, Samuelsson B (1975) Thromboxanes: a new group of biologically active compounds derived from prostaglandin endoperoxides. Proc Natl Acad Sci USA 72: 2994-2998
2. Moncada S, Vane JR (1979) Pharmacology and endogenous roles of prostaglandin endoperoxides, thromboxane $A_{2}$ and prostacyclin. Pharmacol Rev 30: 293-331

3. Kalofoutis A, Lekakis J (1981) Changes of platelet phospholipids in diabetes mellitus. Diabetologia 21: 540-543

4. Morita I, Takahashi R, Ito H, Orimo H, Murota S (1983) Increased arachidonic acid content in platelet phospholipids from diabetic patients. Prostagland Leuk Med 11: 33-41

5. Bills TK, Smith JB, Silver MJ (1976) Metabolism of ${ }^{14} \mathrm{C}$-arachidonic acid by human platelets. Biochim Biophys Acta 424: 303-314

6. Bligh EG, Dyer WJ (1959) A rapid method of total lipid extraction and purification. Can J Biochem Physiol 37:911-917

7. Morita I, Saito Y, Chang WC, Murota S (1983) Effects of purified eicosapentaenoic acid on arachidonic acid metabolism in cultured murine aortic smooth muscle cell, vessel wall and platelets. Lipids 18: 42-49

8. Allain CC, Poon LS, Chan CSG, Richmond W, Fu PC (1974) Enzymatic determination of total serum cholesterol. Clin Chem 20: $470-475$

9. Lehnus G, Smith L (1978) Automated procedure for kinetic measurement of total triglycerides (as glycerol) in serum with the Gilford System 3500. Clin Chem 24:27-31

10. Shimizu S, Inoue $K$, Tani $Y$, Yamada $H$ (1979) Enzymatic microdetermination of serum fatty acids. Anal Biochem 98: 341-345

11. Russell FA, Deykin D (1976) The effect of thrombin on the uptake and transformation of arachidonic acid by human platelets. Am J Hematol 1: $59-70$

12. Ziboh VA, Maruta H, Lord J, Cagle WD, Lucky W (1979) Increased biosynthesis of thromboxane $\mathrm{A}_{2}$ by diabetic platelets. Eur J Clin Invest 9: 223-228

13. Butkus A, Skrinska VA, Schumacher OP (1980) Thromboxane production and platelet aggregation in diabetic subjects with clinical complications. Thromb Res 19:211-223

14. Halushka PV, Rogers RC, Loadholt CB, Colwell JA (1981) Increased thromboxane synthesis in diabetes mellitus. J Lab Clin Med 97: 87-96

15. Jones DB, Carter RD, Haitas B, Mann JI (1983) Low phospholipid arachidonic acid values in diabetic platelets. Br Med J 286: 173-175

16. Faas FH, Carter WJ (1980) Altered fatty acid desaturation and microsomal fatty acid composition in the streptozotocin diabetic rat. Lipids 15:953-961

17. Ayala S, Gaspar G, Brenner RR, Peluffo RO, Kunau W (1973) Fate of linoleic, arachidonic and docosa-7,10,13,16-tetraenoic acids in rat testicles. J Lipid Res 14: 296-305

18. Bills TK, Smith JB, Silver MJ (1977) Selective release of arachidonic acid from the phospholipids of human platelets in response to thrombin. J Clin Invest 60: 1-6

19. Wilson DB, Prescott SM, Majerus PW (1982) Discovery of an arachidonoyl Coenzyme A synthetase in human platelets. J Biol Chem 257: 3510 -3515

20. Lagarde M, Burtin M, Berciaud P, Blanc M, Velardo B, Dechavanne $M(1980)$ Increase of platelet thromboxane $A_{2}$ formation and of its plasmatic half-life in diabetes mellitus. Thromb Res 19: 823-830

21. Webster J, Lewis PJ, MacDermot J, Hensby CN (1981) Forearm ischaemia as a test of prostacyclin production: studies in normal subjects and in patients with diabetes mellitus. Prostagland Med 6: 661-667

Received: 23 February 1983

and in revised form: 10 October 1983

Dr. R. Takahashi

Endocrinology and Metabolism Section

Tokyo Metropolitan Geriatric Hospital

35-2 Sakaecho

Itabashiku

Tokyo 173, Japan 